\title{
Excitatory Action of ATP on Embryonic Chick Muscle
}

\author{
Richard I. Hume and Marcia G. Honig \\ Division of Biological Sciences, Natural Science Building, University of Michigan, Ann Arbor, Michigan 48109
}

\begin{abstract}
It has been suggested that ATP might play a role in synaptic transmission at developing vertebrate neuromuscular junctions. To increase our understanding of the events underlying synapse formation, we have used intracellular recording and patch clamp recording to examine the response of chick myoblasts and myotubes to ATP and other nucleotides. ATP, applied at micromolar concentrations, has a potent depolarizing action on chick myoblasts and myotubes. The ATP depolarization declines during prolonged application of ATP and shows no recovery for at least 20 min after the removal of ATP. The physiological event that underlies the ATP response has a reversal potential near $0 \mathrm{mV}$ and is due to a conductance increase. However, contrary to our expectations, in a series of nearly 200 cell-attached and outside-out patch recordings, we did not detect single-channel currents that were related to ATP.

The myotube ATP receptor is pharmacologically distinct from putative ATP receptors in other systems. It is not activated by ADP, AMP, or adenosine. Furthermore, the nonhydrolyzable ATP analogs, AMP-PNP, $\alpha, \beta$-meATP, and $\beta, \gamma$-meATP (respectively, 5 -adenylylimido diphosphate; $\alpha, \beta$-methylene adenosine 5 -triphosphate; and $\beta, \gamma$-methylene adenosine 5 -triphosphate), which are potent ATP agonists in other systems, have no depolarizing action on myotubes. The ATP receptor is also distinct from the nicotinic $\mathrm{ACh}$ receptor since responses to ATP are unaffected by the nicotinic antagonists $d$-tubocurarine and $\alpha$-bungarotoxin. We therefore applied $\alpha$-bungarotoxin to nervemuscle co-cultures in the hope of uncovering an additional component of the postsynaptic potential, which might represent a synaptic action of ATP. Under these experimental conditions no evidence indicative of a postsynaptic action of ATP released from nerve terminals was observed.
\end{abstract}

The pioneering experiments of Dale demonstrated that $\mathrm{ACh}$ is used as a neurotransmitter at mature vertebrate neuromuscular junctions (Dale et al., 1936), and until recently it has seemed unnecessary to consider additional transmitter candidates. Several developments have made the completeness of our knowledge seem less sure. It is now widely recognized that many mature neurons contain more than one neurotransmitter (Hökfelt et al., 1984); in at least some instances, both substances have physiological effects on the postsynaptic cell (see, for example, Jan et al., 1983). Furthermore, it is now realized that the transmitter manufactured by a mature neuron may differ from the transmitter synthesized by that same neuron at an earlier developmental stage. For instance, neurons from the sympathetic nervous system may switch from using norepinephrine to using

\footnotetext{
Received Mar. 28, 1985; revised May 25, 1985; accepted May 28, 1985.

We thank Dr. R. W. Aldrich and Dr. L. W. Role for helpful comments on the manuscript, and $E$. Wojcik for technical assistance. This work was supported by National Institutes of Health Grant NS21043, by a Rackham Faculty Research Grant, and by a research fellowship to R. H. from the Alfred P. Sloan Foundation. Correspondence should be addressed to Dr. Hume.

Copyright (C) 1986 Society for Neuroscience $0270-6474 / 86 / 030681-10 \$ 02.00 / 0$
}

ACh during development both in vitro (Furshpan et al., 1976; Johnson et al., 1976) and in vivo (Landis and Keefe, 1983).

In this paper we explore the possibility that ATP might be an additional neurotransmitter active at newly formed neuromuscular junctions. This possibility was suggested by recent observations made by Kolb and Wakelam (1983). They reported that cultured chick myoblasts and myotubes display a class of channels that open in the presence of micromolar levels of ATP. Since ATP is present in the synaptic vesicles of cholinergic terminals at an appreciable concentration (reviewed in Castel et al., 1984; Zimmermann, 1982) and is released upon stimulation from at least some cholinergic neurons (Silinsky, 1975), these results suggest the intriguing possibility that ATP may serve as cotransmitter at developing neuromuscular junctions. To examine this possibility, we undertook a detailed study of the responsiveness of chick myoblasts and myotubes to ATP. Here we report that ATP, at concentrations likely to be present in the synaptic cleft, has a potent depolarizing action.

\section{Materials and Methods}

\section{Cell culture}

Muscle cultures werc prepared with slight variations from the methods described by Fischbach (1972). Pectoral muscle was dissected from 11 d chick embryos, minced into small pieces, and placed into a calciumand magnesium-free solution (Pucks saline) without added enzymes. After a $20 \mathrm{~min}$ incubation at room temperature, the suspension was triturated in culture medium and then filtered through a double layer of lens paper to remove muscle cell fragments and undissociated muscle cell clumps. The density of cells was estimated by hemocytometer counts, and cells were plated onto gelatin-coated tissue culture dishes at $150,000-$ 250,000 cells per $35 \mathrm{~mm}$ dish. The culture medium, Eagle's MEM with Earles salts (Gibco), was supplemented with 10\% heat-inactivated horse serum (Gibco), penicillin-streptomycin ( 50 units $/ \mathrm{ml}, 50 \mu \mathrm{g} / \mathrm{ml}$ ) and conalbumin (40 $\mu \mathrm{g} / \mathrm{ml}$; Sigma). Ii et al. (1982) have shown that conalbumin (ovotransferrin) can replace the chick embryo extract used by previous investigators to promote myoblast differentiation. Cultures were maintained in a humidified incubator at $37^{\circ} \mathrm{C}$ with an atmosphere of $95 \%$ air, $5 \% \mathrm{CO}_{2}$. At 3-4 d the cultures were treated for $2-3 \mathrm{~d}$ with medium containing $10^{-5} \mathrm{M}$ cytosine arabinoside (Sigma) to kill dividing fibroblasts (Fischbach, 1972). Cultures were fed every 3-4 d thereafter with fresh medium. In some experiments we prevented myoblasts from fusing by lowering the concentration of free calcium in the medium (Paterson and Strohman, 1972; Shainberg et al., 1971) by adding 2.75 mм EGTA to our normal medium $6 \mathrm{hr}$ after the cells wcrc plated. At this concentration; fusion was very rare in our cultures for at least $3 \mathrm{~d}$. We found that the useful range of EGTA concentration was very narrow. At EGTA concentrations below $2.5 \mathrm{~mm}$, the extent of fusion appeared nearly normal, while at $3.0 \mathrm{~mm}$ and above, all the myoblasts died. In this paper we use the term "myoblast" to refer to spindle-shaped mononucleated cells, and the term "myotube" to refer to all multinucleated cells, regardless of the stage of differentiation.

In a few experiments, dissociated chick ciliary ganglion neurons were added to established muscle cultures. Ganglia from 8-10 d embryos were dissociated following a $20 \mathrm{~min}$ incubation in $0.01 \%$ trypsin in $\mathrm{Ca}^{2+}, \mathrm{Mg}^{2+}$-free Pucks saline, and added to 8-15 d musclc cultures at a density equivalent to one ganglion per $35 \mathrm{~mm}$ dish. 


\section{Recording methods}

Culture dishes were mounted on the stage of an inverted microscope (Zeiss IM 35) and viewed with phase-contrast optics. In order to maximize stability for long-term recordings, the micromanipulators (Narashige MO 103) were mounted on the microscope stage, and the microscope was rigidly mounted on an air table. In most experiments the cells were bathed in an external solution containing $116 \mathrm{~mm} \mathrm{NaCl}, 5$ mм KCl, $5.4 \mathrm{~mm} \mathrm{CaCl}_{2}, 1.6 \mathrm{~mm} \mathrm{MgSO}_{4}, 1.3 \mathrm{~mm} \mathrm{NaHPO}_{4}, 6.3 \mathrm{~mm}$ glucose, and $10 \mathrm{~mm}$ HEPES (pH 7.4). In some experiments we used an external solution intended to block most voltage-dependent channels. It contained $100 \mathrm{~mm} \mathrm{NaCl}, 4 \mathrm{~mm} \mathrm{KCl}, 4 \mathrm{~mm} \mathrm{CoCl}_{2}, 1 \mathrm{~mm} \mathrm{MgCl}_{2}, 10^{-7} \mathrm{M}$ TTX (Sigma), $20 \mathrm{~mm}$ tetraethylammonium chloride (TEA, Eastman), $5 \mathrm{~mm}$. 4-aminopyridine (4-AP, Sigma), $5 \mathrm{~mm}$ glucose, and $12.5 \mathrm{~mm}$ HEPES (pH 7.4). For cell-attached patch clamp recording, the electrodes were filled with external solution plus drug. For outside-out patch recording, the electrode contained $140 \mathrm{~mm} \mathrm{KCl}, 2 \mathrm{mM} \mathrm{MgCl}, 1 \mathrm{~mm} \mathrm{CaCl}_{2}$, $11 \mathrm{~mm}$ EGTA, and $10 \mathrm{~mm}$ HEPES (pH 7.2). All experiments were performed at room temperature $\left(20-22^{\circ} \mathrm{C}\right)$.

Intracellular recordings were made with conventional glass microelectrodes filled with $3 \mathrm{M} \mathrm{KCl}$. In all experiments in which it was necessary to change the membrane potential of myotubes, the cells were impaled with two separate microelectrodes placed less than $100 \mu \mathrm{m}$ apart. Single-channel and whole-cell patch clamp recordings were made essentially as described by Hamill et al. (1981), using a List EPC 5 patch clamp amplifier. Data were digitized on line by a 12 bit A/D converter, and stored digitally on disk. For single-channel experiments, data were filtered at $1 \mathrm{kHz}$ and sampled at $2 \mathrm{kHz}$. For intracellular recordings, the sample rate ranged between $2 \mathrm{kHz}$ and $125 \mathrm{~Hz}$. In all figures showing recordings, the digitized data points have been connected by straight lines.

In some experiments, the effect of drugs was assayed by observing the proportion of muscle fibers that contracted. The fibers were viewed at a total magnification of $160 \times$. Contractions ranged from brisk twitches to slow oozing movements, but no effort was made to quantify the type of contraction; we simply scored each fiber as contracting or noncontracting.

\section{Drug application}

Test substances were usually applied by pressure ejection ( $\sim 10$ psi) from micropipettes with tip diameters of $1-5 \mu \mathrm{m}$ (puffer pipettes). The duration of the pressure pulse was accurately controlled by the opening and closing of a solenoid valve in the pressure line. When the solenoid closed, it vented the pipette to the outside, so that no residual pressure could continue to force drug from the pipette. All drugs that were pressure-applied were dissolved in external recording solution. Puffer pipettes were placed about $20 \mu \mathrm{m}$ from the test cell or patch. A possible concern with this method is that drugs might leak out of the pipette and desensitize the receptors even before pressure is applied. Our results with $\mathrm{ACh}$ in the pipette provided a control for this possibility. We saw few, if any, channel openings when small puffers filled with $50 \mu \mathrm{m} \mathrm{ACh}$ were placed near patches, yet puffs from pipettes filled with $500 \mathrm{nM}$ ACh gave a reasonable rate of single-channel openings. Thus, the concentration of drug that reaches a patch due to leakage was less than $1 / 100$ of the concentration in the pipette, which we consider to be negligible.

Putative antagonists were added to the bath. We used $d$-tubocurarine at $50 \mu \mathrm{M}$ and $\alpha$-bungarotoxin at $0.5-5 \mu \mathrm{g} / \mathrm{ml}$.

In some experiments, ACh or ATP (0.5-1 $\mathrm{M}$ in distillcd watcr) was applied by iontophoresis from a fine-tipped microelectrode $(>100 \mathrm{M} \Omega)$. Iontophoretic pipettes were placed as close as possible to the test cell or patch. Backing currents of $1-3 \mathrm{nA}$ were used to prevent leakage from the pipette (negative for ACh, positive for ATP).

A variety of nucleotides was applied to myotubes. Their full names and the abbreviations are given here. In the text only the abbreviations are used.

1. ITP; inosine 5 -triphosphate, sodium salt.

2. $\alpha, \beta$-meATP; $\alpha, \beta$-methylene adenosine $5^{\prime}$-triphosphate, lithium salt (abbreviated by others as AMP-CPP).

3. $\beta, \gamma$-meATP; $\beta, \gamma$-methylene adenosine $5^{\prime}$-triphosphate, sodium salt (abbreviated by others as AMP-PCP).

4. ATP- $\gamma-\mathrm{S}$; adenosine $5^{\prime}-O$-(3-thiotriphosphate), lithium salt (abbreviated by others as AMP-PPS).

5. AMP-PNP; 5-adenylylimido diphosphate, lithium salt.

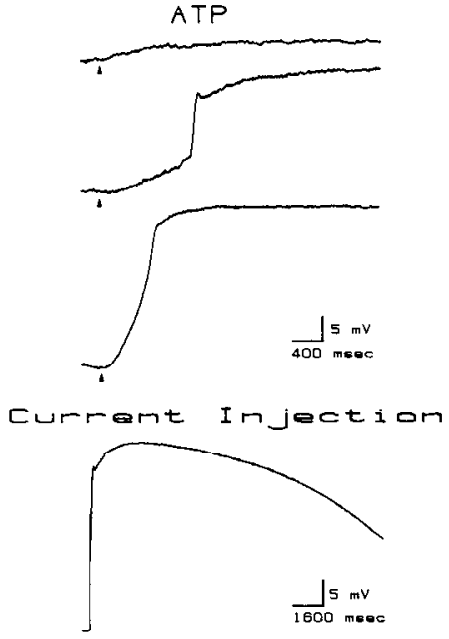

Figure 1. Top, Depolarizing action of ATP on chick myotubes. The intracellularly recorded responses to $10 \mu \mathrm{M}$ ATP applied from puffer pipettes are shown for three different myotubes. The puffs began at the times indicated (arrowheads) and lasted $1 \mathrm{sec}$. In the middle and lower traces, the ATP responses exceeded threshold for an active response. Bottom, The active response of chick myotubes is very prolonged. This myotube was penetrated with two microelectrodes. A $50 \mathrm{msec}, 4 \mathrm{nA}$ depolarizing current pulse was passed through one electrode to initiate an active response. The membrane potential (recorded by the other electrode) showed an initial passive depolarization, and then the two components of the active response. The plateau phase of this spike lasted more than $20 \mathrm{sec}$.

ADP, AMP, and GTP were obtained as sodium salts, adenosine as a hemisulfate salt, and ATP as either the sodium or magnesium salt. Both the magnesium and sodium salts of ATP were used without apparent difference. All chemicals were obtained from Sigma, except ATP$\gamma-\mathrm{S}$, which was obtained from Pharmacia/PL.

To minimize the possibility of contaminating the drug solutions, we made disposable pipette fillers. A $1 \mathrm{ml}$ polyethylene syringe was pulled over a small flame to form a thin, elongated tip that would be inserted into a micropipette for backfilling. A separate filler was made for each concentration of each drug.

\section{Results}

\section{Physiological properties of the $A T P$ response}

\section{Depolarizing action of ATP on myoblasts and myotubes}

To characterize the response of cultured muscle cells to ATP, we made intracellular recordings from myoblasts and myotubes between 1 and $27 \mathrm{~d}$ in culture. Myoblasts were studied with whole-cell intracellular recording (Hamill et al., 1981), while myotubes were studied with conventional intracellular recording. Most myoblasts (13/17) and myotubes (155/189) tested were excited when $10 \mu \mathrm{M}$ ATP was applied to their surface from a puffer pipette. ATP-evoked depolarizations began 100-500 msec after the onset of a puff. More precise estimates of latency, obtained from experiments in which ATP was applied from iontophoretic pipettes positioned very close to the muscle surface, indicated that the latency could be as short as $20 \mathrm{msec}$. ATP depolarized many myotubes beyond threshold for an active response (Fig. 1). These active responses were of extremely long duration (1-30 sec) and obscured the time course of the underlying ATP depolarization. The rapid rising phase of the active response is a TTX-sensitive sodium spike (Kano et al., 1972), while the plateau is caused by activation of voltagedependent calcium (Kano and Shimada, 1973) and chloride (Fukuda, 1974; Fukuda et al., 1976) channels. The active responses evoked by injection of depolarizing current were just as prolonged as those evoked by ATP (Fig. 1). 


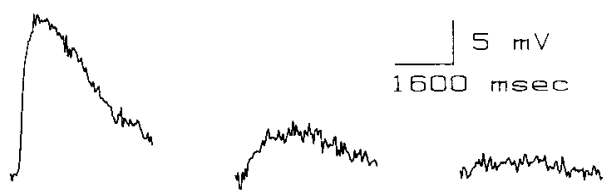

Figure 2. ATP responses decline profoundly with repeated application. The intracellularly recorded responses evoked by three sequential applications of $10 \mu \mathrm{M}$ ATP to the same spot on a myotube are shown. Each application of ATP began $200 \mathrm{msec}$ after the start of the trace, and lasted 100 msec. There was no apparent recovery between trials. The intertrial intervals were 2 and $10 \mathrm{~min}$, respectively.

\section{Long-term desensitization of the ATP response}

It quickly became apparent that the ATP response was not stable over time. During any single application of ATP, the response declined with time, even in the continued presence of ATP. This effect appeared to be similar to the desensitization seen with long applications of $\mathrm{ACh}$. However, unlike the $\mathrm{ACh}$ responses, there was little apparent recovery (Fig. 2). A second application of ATP several minutes later always gave a response that was smaller than the first. Additional applications produced even smaller responses. Typically, beyond three to five applications of ATP, no detectable response was observed. Even 20 min after the initial ATP application, there was no indication of recovery. Therefore, this long-term decrement differs from the desensitization of $\mathrm{ACh}$ receptors, which recovers with multiple time constants over a period of several minutes (Feltz and Trautmann, 1982); however, for convenience we will refer to it as desensitization. It is interesting to note that a rapid and longlasting desensitization is also a characteristic of the ATP response of mammalian sensory neurons (Jahr and Jessell, 1983; Krishtal et al., 1983) but not of guinea pig vas deferens smooth muscle (Sneddon and Westfall, 1984). The long-term desensitization of the ATP response prevented us from performing repetitive trials on the same fiber; instead we were forced to sample a series of fibers in order to further characterize the ATP responsiveness of myotubes.

\section{ATP-evoked contraction}

As might be expected from the presence of suprathreshold responses, many myotubes visibly contracted when ATP was applied to their surface. In cultures younger than $3 \mathrm{~d}$, there were no contractile cells, and at $3 \mathrm{~d}$ only $2 / 40$ cells contracted in response to $10 \mu \mathrm{M}$ ATP. This presumably represents an immaturity in excitation-contraction coupling or in the contractile machinery, since at this stage only $3 / 40$ cells contracted in response to $10 \mu \mathrm{M} \mathrm{ACh}$. In cultures $5 \mathrm{~d}$ or older, the majority of myotubes tested (306/447) contracted in response to $10 \mu \mathrm{M}$ ATP.

Because of long-term desensitization, it was not possible to construct a dose-response curve for ATP by recording from individual myotubes. Instead, to construct an approximate doseresponse curve for ATP action, we applied a series of concentrations to mature myotubes and counted the number of fibers that contracted (Fig. 3). Each fiber was tested only once. These experiments indicated that $500 \mathrm{nM}$ ATP can elicit contraction in some myotubes and that $10 \mu \mathrm{M}$ is sufficient to activate the maximal number of fibers. It should be noted that the assay of contraction is several steps removed from receptor activation. In addition to the ligand binding properties of the receptor, this assay depends on the number of receptors present, the input resistance of the cell, the resting potential, the threshold for spike initiation, and the state of the contractile apparatus. For these reasons, we do not feel it is appropriate to draw quantitative conclusions from these curves. However, on the basis of these experiments, we chose to use $10 \mu \mathrm{M}$ ATP in most subsequent experiments.
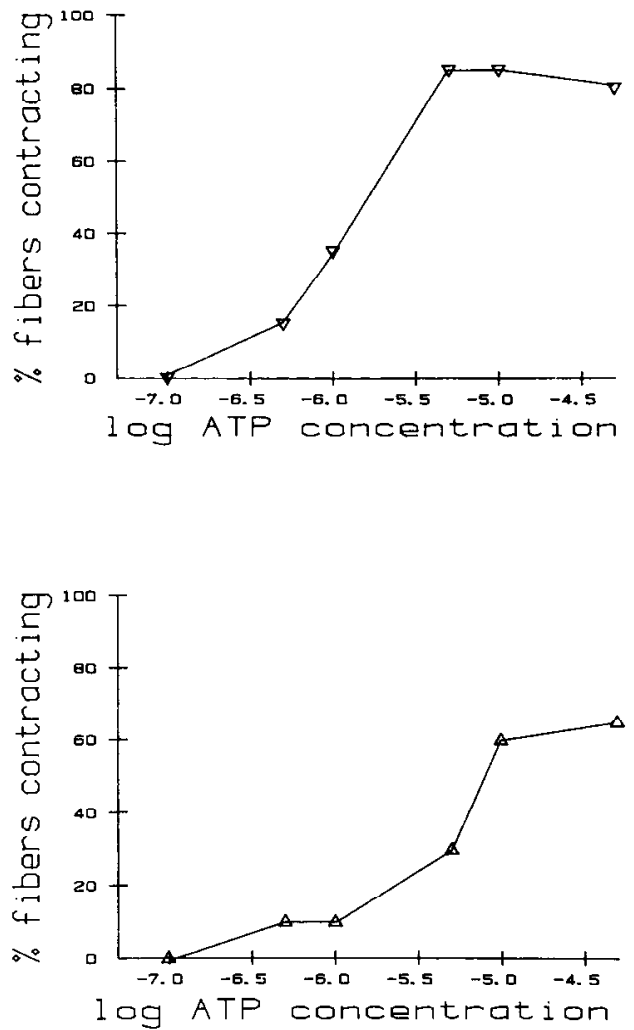

Figure 3. Dose-response curves for ATP action. ATP was applied from a series of puffer pipettes to the surfaces of myotubes while each fiber was observed for the presence of a contractile response. At least 20 myotubes were tested for each concentration. The two graphs show the results obtained from two different $11 \mathrm{~d}$ cultures. These graphs also illustrate that the proportion of fibers that contracted to saturating levels of ATP varied among cultures.

\section{Voltage dependence of ATP action}

To determine the mechanism by which ATP acts, we first examincd whether ATP causes a conductance changc. We measured input conductance by applying small, hyperpolarizing, constant-current pulses. In normal external solution, the membrane conductance increased considerably with depolarization. This made it extremely difficult to separate any conductance change due directly to ATP action from the conductance change due to the ATP-evoked depolarization. However, when most of the voltage-dependent ionic channels were blocked, the current-voltage relationship was less nonlinear. Sodium and potassium channels were blocked by the addition of TTX, TEA, and 4-AP, and calcium channels were blocked by substituting cobalt for calcium. Recordings made in this solution showed that ATP caused a net conductance increase. Figure $4 A$ shows that the ATP-evoked depolarization was associated with a conductance increase, while Figure $4 B$ shows that passive depolarization over the same voltage range caused a much smaller conductance increase. The input conductance in the presence and absence of ATP is plotted in Figure $4 C$. For the six cells tested in this way, the peak conductance in the presence of ATP was $3.25 \pm 1.25$ (mean $\pm \mathrm{SD}$ ) times the conductance at the same potential without ATP.

To gain insight into the ionic basis of ATP action, we tested myotubes at a variety of membrane potentials. At all potentials more negative than rest (we tested down to $-140 \mathrm{mV}$ ), АTP produced substantial depolarizations. The channel-blocking solution allowed us to depolarize myotubes sufficiently to test for a reversal potential. Figure 5 demonstrates that the response to 

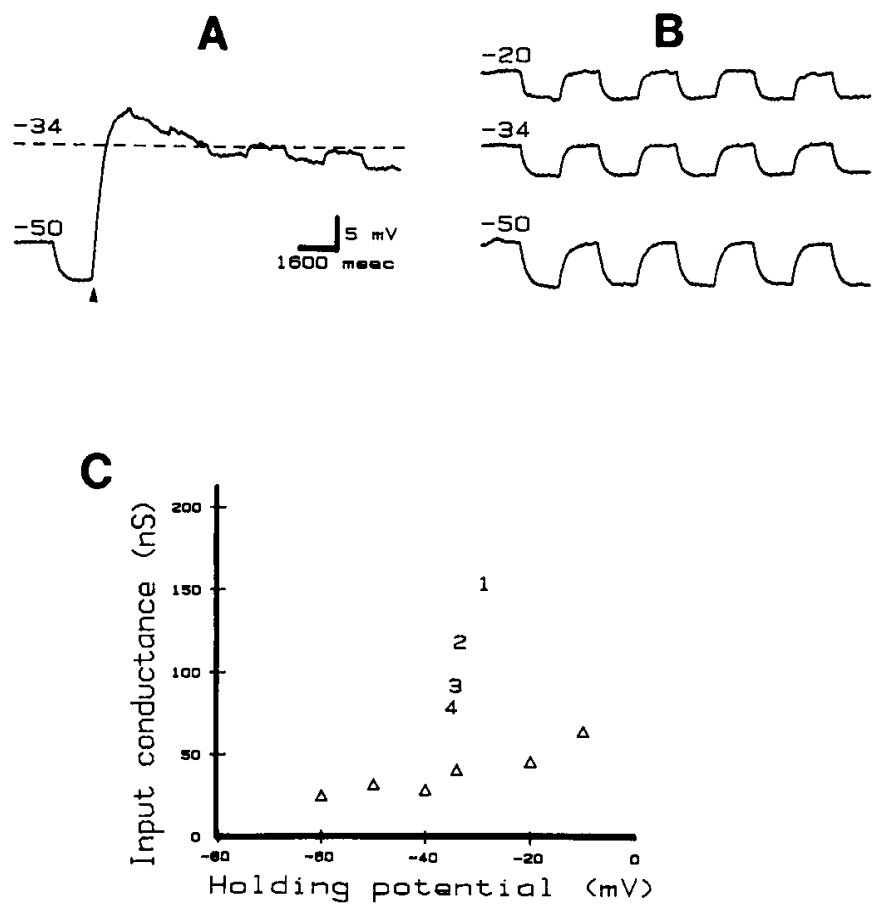

Figure 4. ATP causes an increase in membrane conductance. These experiments were performed in an external solution that blocked most voltage-dependent channels. A, Application of $10 \mu \mathrm{M}$ ATP (arrowhead) for $1.6 \mathrm{sec}$ evoked a depolarization. Constant-current pulses $(-0.2 \mathrm{nA})$ were applied before and during the ATP application so that the input conductance could be measured. Separate electrodes were used for passing current and measuring potential. $B$, Membrane potential was set at a variety of levels, and current pulses $(-0.2 \mathrm{nA})$ were applied so that input conductance could be measured in the absence of ATP. Same cell as $A$. $C$, The data from $A$ and $B$ are plotted. Triangles show measurements of input conductance made in the absence of ATP. The numbers represent a series of measurements made in the presence of ATP. Individual numbers indicate the sequence in which the measurements were made. Thus, the first measurement, made near the peak of the response, showed a bigger conductance change than measurements made later.

ATP reverses. When this myotube was depolarized to $+50 \mathrm{mV}$ ATP evoked a negative-going response, while at $-60 \mathrm{mV}$ ATP evoked a positive-going response. Because of the long-term decrement in the ATP response described above, it is unlikely that the conductance change was the same in sequential trials; thus, it is not appropriate to draw a line between points on a currentvoltage curve to estimate the reversal potential. Instead, we studied a series of myotubes at different potentials. ATP made the membrane potential more negative at all potentials above $+10 \mathrm{mV}(n=11)$ and more positive at all potentials below -20 $\mathrm{mV}$; therefore, the reversal potential must be in this range. A reversal potential near $0 \mathrm{mV}$ is consistent with an ion channel that is relatively nonselective among cations, like the ACh receptor channel (Takeuchi and Takeuchi, 1960) and the calciumactivated nonselective cation channel (Colquhoun et al., 1981; Yellen, 1982).

\section{Extracellular site of ATP action}

Intracellular ATP is involved in many cellular processes, including energy metabolism and muscle contraction. We therefore considered the possibility that extracellularly applied ATP might somehow traverse the membrane and act at an intracellular site. To address this possibility, we performed experiments like the one illustrated in Figure 6. Myotubes were impaled with two microelectrodes, one filled with $3 \mathrm{M} \mathrm{KCl}$, the other with $1 \mathrm{~m}$ NaATP. A hyperpolarizing current pulse was applied to the

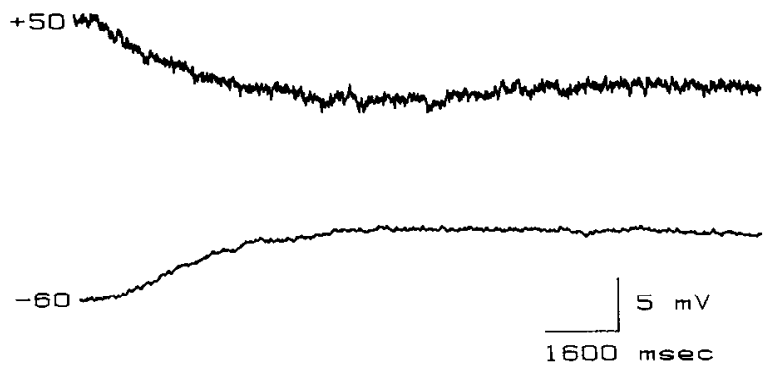

Figure 5. ATP-evoked potentials reverse in sign. This experiment was performed in an external solution that blocked most voltage-dependent channels. ATP $(10 \mu \mathrm{M})$ was applied from a puffer for $0.8 \mathrm{sec}$ starting 80 msec after the beginning of each trace. Membrane potential was set by passing current through one microelectrode and was measured with a second microelectrode. The trace at $-60 \mathrm{mV}$ was obtained second, so the conductance change is probably smaller than the conductance change for the trace at $+50 \mathrm{mV}$.

ATP pipette to apply ATP iontophoretically to the inside of the cell. The $\mathrm{KCl}$ electrode recorded a hyperpolarization, which reflected the cell's input resistance, but no ATP-evoked depolarization. To verify that ATP was being ejected from the ATP pipette, the pipette was then removed to just outside the myotube. When the same hyperpolarizing pulse was now applied, a depolarizing ATP response was seen. Similar results were obtained for six myotubes. From these experiments, we conclude that the ATP effect is mediated by a receptor exposed on the outside of the cell surface.

\section{Pharmacological characteristics of the ATP response}

\section{Nucleotide sensivity}

To examine the pharmacological profile of the ATP receptor, we tested a variety of other nucleotides for possible depolarizing effects on chick myotubes. For each myotube, we first applied the test nucleotide $(50 \mu \mathrm{M})$ and then ATP, to be sure that tests were not being made on desensitized myotubes. Figure 7 illustrates that neither adenosine, AMP, nor ADP had a detectable depolarizing effect on chick myotubes. This result was verified in at least five myotubes tested by intracellular recording, and 20 myotubes tested for a contractile response. Thus, this effect has a pharmacological profile different from that of either the adenosine or ATP receptors that have been described in other systems (Burnstock, 1981). GTP and ITP, tested in a similar manner, did not evoke contraction in myotubes. In most of the myotubes tested with intracellular recording, application of these nucleotides was not associated with a potential change. However, in a few myotubes, $1-3 \mathrm{mV}$ depolarizations or hyperpolarizations were seen, which probably represented small baseline

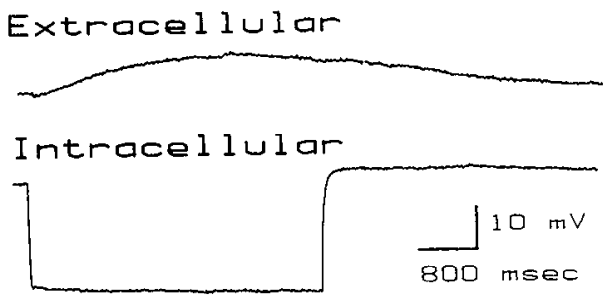

Figure 6. ATP acts at an extracellular site. This myotube was impaled with one microelectrode for intracellular recording and a second iontophoretic microelectrode containing $1 \mathrm{~m}$ NaATP. ATP applied intracellularly by a $2 \mathrm{nA}$ hyperpolarizing current pulse did not evoke any depolarization. However, applying the same current pulse after removing the iontophoretic pipette to just outside the cell membrane depolarized the myotube. 

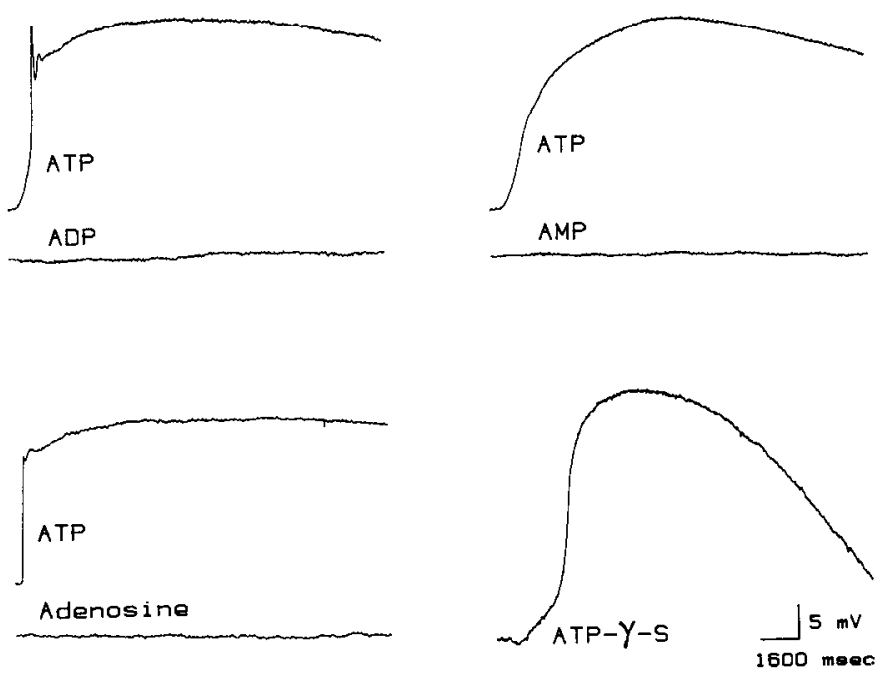

Figure 7. Effect of other adenine derivatives on myotubes. ADP, AMP, and adenosine did not depolarize myotubes. ATP- $\gamma$-S was the only one of a series of ATP analogs tested that had a depolarizing action. For each pair of recordings, the test substance was applied before ATP. ADP, AMP, and adenosine were applied at $50 \mu \mathrm{M}$, while ATP and ATP$\gamma-\mathrm{S}$ were applied at $10 \mu \mathrm{M}$.

shifts. Thus, ATP is by far the most potent depolarizing agent among the naturally occurring nucleotides tested.

We also tested a series of ATP analogs that act as agonists or antagonists in other systems. AMP-PNP, $\alpha, \beta$-meATP, $\beta, \gamma-$ meATP, and ATP- $\gamma$-S are ATP-like molecules that are resistant to hydrolysis by ATPases (Gratecos and Fisher, 1974; Moody and Burnstock, 1982). Of these molecules, only ATP- $\gamma-\mathrm{S}$ had a detectable effect on chick myotubes. At $10 \mu \mathrm{M}$ it caused depolarization in four out of six fibers (Fig. 7), while at $50 \mu \mathrm{M}$ it caused 33 out of 41 fibers to contract. The ATP- $\gamma-\mathrm{S}$ response showed long-term desensitization with repeated application. Furthermore, once desensitized by ATP- $\gamma-\mathrm{S}$, the myotubes were also unresponsive to ATP, that is, ATP and ATP- $\gamma-\mathrm{S}$ crossdesensitize.

Neither AMP-PNP, $\alpha, \beta$-meATP, nor $\beta, \gamma$-meA'TP caused a potential change in myotubes $(n=10$ for each) nor did they evoke contraction ( $n=20$ for each). All three of these substances act as ATP agonists in other systems (see Discussion). One of these substances, $\alpha, \beta$-meATP, has in addition been shown to be a potent inhibitor of ATP-evoked depolarizations in the guinea pig vas deferens (Sneddon and Burnstock, 1984). Long exposure to $\alpha, \beta$-meATP had no obvious inhibitory effect on the ATP responsiveness of myotubes. Most myotubes (9/11) were depolarized by ATP after being bathed in a solution containing $3 \mu \mathrm{M} \alpha, \beta$-meATP for $30 \mathrm{~min}$, a treatment that would have been maximally effective in the vas deferens. Because of the longterm desensitization of the ATP response, we could not test the same fibers with ATP before and after the $\alpha, \beta$-meATP application. We therefore cannot rule out a small inhibitory effect. However, it is clear that $\alpha, \beta$-meATP is not particularly potent as an antagonist in this system.

\section{Nicotinic ACh receptor antagonists}

The single-channel currents described by Kolb and Wakelam (1983) were very similar in their conductance properties to the $\mathrm{ACh}$ receptor channels. It therefore seemed possible that ATP might exert its action by serving as an ACh receptor agonist. To test this possibility, we examined how the ATP response of myotubes was affected by nicotinic ACh receptor antagonists (Fig. 8). In the presence of sufficient $\alpha$-bungarotoxin to completely block ACh-evoked contraction, 49 of 78 fibers contracted
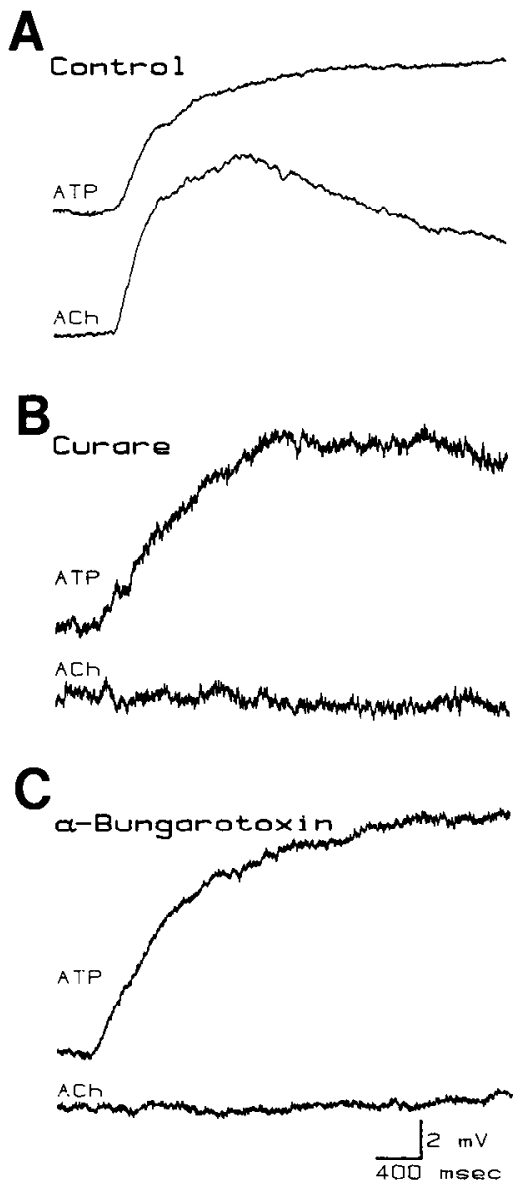

Figure 8. The ATP response is not blocked by nicotinic antagonists. Each panel shows intracellular recordings of myotube responses to puffs from ATP- and ACh-filled pipettes. $A$, Control records. In $B, d$-tubocurarine was added to the bath at $50 \mu \mathrm{M}$. In $C, \alpha$-bungarotoxin was added to the bath to a final concentration of $1 \mu \mathrm{g} / \mathrm{ml}$. ATP was applied at $10 \mu \mathrm{M}$. ACh was applied at $1 \mu \mathrm{M}$ for $A$ and $B$ and $10 \mu \mathrm{M}$ for $C . A-$ $C$ represent responses from three different myotubes.

to ATP, and in the presence of sufficient $\alpha$-bungarotoxin to completely block ACh-evoked depolarizations, 13 of 14 fibers were depolarized by ATP. Curare treatment gave similar results, although at $50 \mu \mathrm{M}$ it often did not completely block ACh-evoked depolarizations. Thus, nicotinic antagonists do not block the ATP response.

We also tested for cross-desensitization between $\mathrm{ACh}$ and ATP. As noted above, a large pulse of ACh leaves most ACh receptors in the desensitized state and, similarly, after a large pulse of ATP, most ATP receptors are desensitized. If ATP and $\mathrm{ACh}$ act on the same receptor, then ACh, applied immediately after a large pulse of ATP, should be ineffective. Figure $9 A$ illustrates that a desensitizing application of ATP has no apparent effect on the ACh sensitivity of a myotube. The ACh response immediately after a desensitizing application of ATP was neither enhanced nor attenuated. Similar results were obtained from five additional myotubes. Figure $9 B$ illustrates one example of the converse experiment: In all seven cases, large ATP responses could be evoked immediately after a desensitizing application of $\mathrm{ACh}$. On the basis of the failure of nicotinic antagonists to block ATP responses and the lack of cross-desensitization, we conclude that it is unlikely that the major site of ATP action is at the ACh receptor.

\section{Single-channel recording}

Our original intention was to study ATP-sensitive channels in outside-out patches in order to compare their properties with 
A

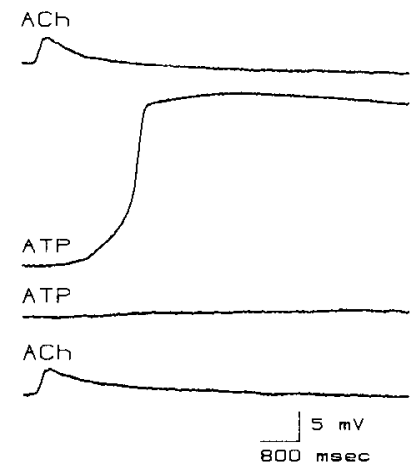

B

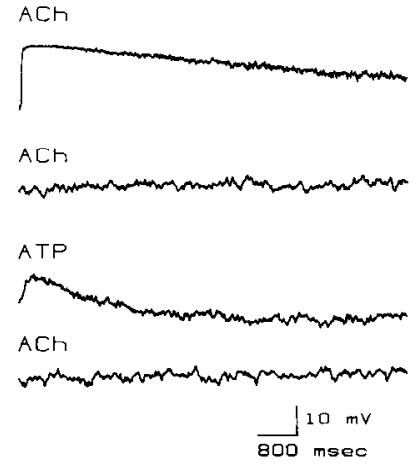

Figure 9. The ACh and ATP responses do not interact. $A$, The ACh response is not affected by a desensitizing application of ATP. A test pulse of $\mathrm{ACh}$ from an iontophoretic pipette ( $200 \mathrm{msec},-2 \mathrm{nA}$ backing current, $1.9 \mathrm{nA}$ ejection current) produced the depolarizing response shown in the top trace. Three successive $1 \mathrm{sec}$ puffs of $10 \mu \mathrm{M}$ ATP were then delivered (intertrial interval was about $2 \mathrm{sec}$ ) to produce complete desensitization to ATP. The large depolarization shown in the second trace is the response to the first puff. By the third puff (third trace), the trace was flat, indicating that ATP desensitization was complete. The response to ACh applied immediately thereafter (bottom trace) was very similar to the initial ACh response. A final application of ATP (not shown) indicated that desensitization to ATP remained complete. In this experiment, ACh was applied iontophoretically and ATP from a puffer, to ensure that the region in which ACh receptors might be activated would be completely superfused by ATP. Drug applications began $200 \mathrm{msec}$ after the start of each trace. These intracellular recordings were made from a myotube in a $14 \mathrm{~d}$ culture. $B$, An ATP response can be evoked when ACh receptors are completely desensitized. An initial application of $10 \mu \mathrm{M}$ ACh from a puffer pipette produced the depolarization shown in the first trace. Continuous application of 10 $\mu \mathrm{M} A C h$ from the puffer was then begun to achieve complete desensitization of ACh receptors. The absence of a response to a second puff of ACh applied 1 min later (second trace) verified that desensitization was complete. At this time, a test puff of $10 \mu \mathrm{M}$ ATP depolarized the cell substantially (third trace), although the ACh receptors remained completely desensitized (fourth trace). ACh superfusion was then discontinued, allowing the ACh receptors to recover from desensitization. A puff of ACh applied 2 min later depolarized the cell (not shown). This experiment was performed on a myoblast, whose small size ensured that drugs would superfuse the entire cell surface. All puffs illustrated began at the start of the trace and lasted $1 \mathrm{sec}$. These recordings were made in the whole-cell mode. Each trace began near the rest potential of $-30 \mathrm{mV}$.

those of ACh receptor channels. Since the vast majority of myotubes were depolarized by ATP, we were quite surprised that, in over 100 outside-out patches (from myotubes 4 to $15 \mathrm{~d}$ in culture tested with $1-50 \mu \mathrm{M}$ ATP), we never saw any singlechannel activity that was clearly related to the presence of ATP (Fig. 10). Of 131 patches tested in our most recent series of experiments, 107 showed no single-channel activity during the period that $\Lambda T P$ was applied (typically five applications of $2 \mathrm{sec}$ each). The other 24 patches had one to three openings of inward current channels per patch (approximately $20 \mathrm{sec}$ total exposure to ATP). Although these openings occurred in the presence of ATP, we think it unlikely that they were caused by the ATP. Our reasoning is that the frequency with which we saw inward current channels was roughly the same in the presence or absence of ATP. Channel openings in the apparent absence of any agonist have been interpreted as representing spontaneous openings of the ACh receptor channel (Jackson, 1984). In contrast, all patches tested with ACh (0.1-20 $\mu \mathrm{M} ; n>200)$ showed obvious channel openings. In many, but not all, of the experiments with ATPinsensitive patches, we verified that the cell from which the patch was isolated was responsive to ATP. Some cells (like the one illustrated in Fig. 10) were tested with ATP in the whole-

A

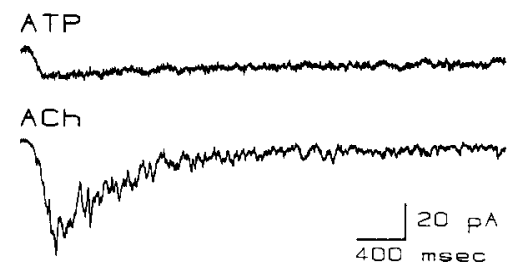

B

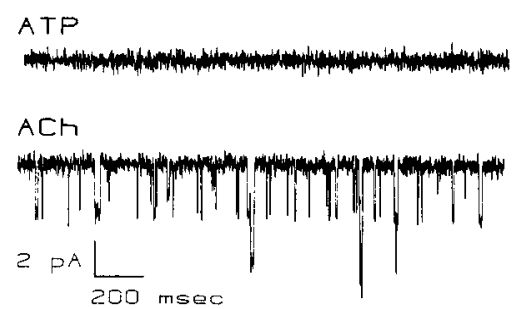

Figure 10. ATP-evoked currents were not detected in outside-out patches. $A$, Response of a chick myotube to ACh $(1 \mu \mathrm{M})$ or ATP $(10$ $\mu \mathrm{M})$ applied by pressure ejection from puffer pipettes. These intracellular current records were made in the whole-cell recording mode prior to isolation of the patch described in $B$. B. Response of an outside-out patch to ACh or ATP. The patch was held at $-80 \mathrm{mV}$. Channel openings were frequent when $\mathrm{ACh}(1 \mu \mathrm{M})$ was applied from a puffer, but no singlechannel events were observed in the presence of $10 \mu \mathrm{M}$ ATP. $1 \mathrm{kHz}$ filtering.

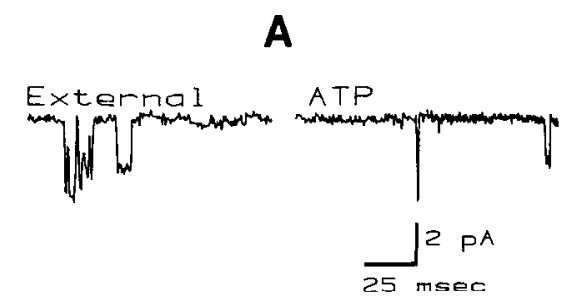

B

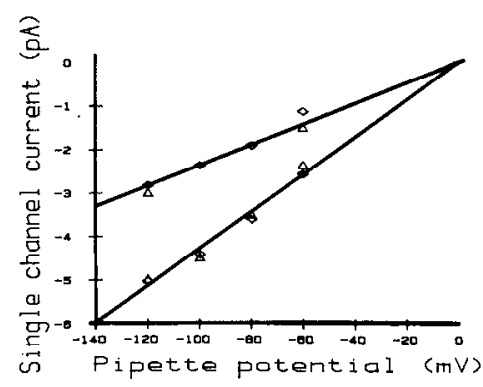

Figure 11. Cell-attached patch recordings from myoblasts. Channel openings were recorded in about half of the cell-attached patches, irrespective of the presence of ATP. Two levels of inward current channels were seen in many patches. $A$, The patch exposed to external solution only was held at rest $-100 \mathrm{mV}$, while the patch exposed to ATP was held at rest $-80 \mathrm{mV}$. $B$, Current-voltage plots of single channels recorded from cell-attached patches on myoblasts. The voltage scale indicates the deviation from resting potential. Diamonds show data obtained from one patch in the presence of ATP; triangles show data from another patch in the absence of ATP. The single-channel conductance for the larger events was $43 \mathrm{pS}$, and for the smaller events, $23 \mathrm{pS}$. 
cell mode prior to isolation of the patch, while other cells were not tested until after we had finished studying the patch, to ensure that the receptors in the patch had not already been desensitized.

In an earlier series of experiments, we saw channel openings in response to puffs from ATP-filled pipettes in some outsideout patches (Hume and Honig, 1984). However, these openings had a number of properties that make it seem unlikely that they were related to the whole-cell ATP response: They were abolished by $\alpha$-bungarotoxin or $d$-tubocurarine, as well as by prior desensitization with $\mathrm{ACh}$. These properties differ from the pharmacological profile of the whole-cell ATP response. Furthermore, by the criteria of single-channel conductance and mean open time, these single-channel currents did not seem to differ from the currents through $\mathrm{ACh}$ receptor channels. The simplest explanation for these openings is that they represented inadvertent contamination of the solution in the ATP pipette with $\mathrm{ACh}$, most probably transferred on our fingers during the process of filling pipettes. This explanation seems reasonable, since $\mathrm{ACh}$, at a concentration of only $100 \mathrm{nM}$, can evoke a significant rate of opening in some patches. Once we became aware of this possibility, we used extreme caution to prevent cross-contamination. For the more recent experiments described above, no channels with these properties were seen in the presence of ATP. Our conclusion from the experiments using outside-out patches is that none of the single-channel events that we have occasionally recorded appears to have the appropriate properties to account for the depolarizing action of ATP on myotubes.

One possible explanation for our failure to detect ATP sensitivity in outside-out patches might be that the ATP channels rapidly lose their ability to function after isolation. Such rapid loss of function is typical of calcium channels in several types of cells (Fenwick et al., 1982), although it is not a property of ACh receptor channels. We therefore performed a series of experiments using cell-attached patches. In some experiments, ATP $(10-100 \mu \mathrm{M})$ was present in the pipette, while in others the pipette contained only the external recording solution. In some cell-attached patches we recorded no single-channel activity. In other cell-attached patches (33/61), with ATP in the pipette, we saw single-channel openings when the pipettes were held at bath potential. At sufficiently negative holding potentials, it was clear that events of at least two discrete amplitudes were present (Fig. 11). These represented channels with conductances of 23 and $43 \mathrm{pS}$, both of which reversed at about the same potential. However, about the same proportion of cell-attached patches studied without ATP in the pipette $(15 / 23)$ showed these types of channel openings. It therefore seems that these channel openings are not related to the presence of ATP. In some cellattachcd patches, the frequency of channel openings increased dramatically when slight negative pressure was applied to the pipette interior (Brehm et al., 1984; Guharay and Sachs, 1984), but this too did not seem to be related to the presence of ATP.

Another possible explanation for our failure to detect ATPsensitive channels is a difference in culture conditions. In order to more closely approximate the growth conditions used by Kolb and Wakelam (1983), we added EGTA to some cultures to inhibit fusion of myoblasts (see Methods). We studied these myoblasts at 2 and $3 \mathrm{~d}$ in culture. Again, we did not see channel openings that could be attributed to ATP in patches from these cells (21 cell-attached patches).

A final possible explanation of why patches appeared to have no functional ATP-activated channels might be that the patches had sealed over to form closed vesicles (see Hamill et al., 1981). This possibility is easily tested by treating the patches in a way expected to cause some other type of channel to open. For outside-out patches, we applied $\mathrm{ACh}$ to activate $\mathrm{ACh}$ receptor channels. For cell-attached patches and some outside-out patches, we applied depolarizing ramp stimuli to evoke the opening of voltage-dependent outward current channels. We verified that most of the patches we studied were functional by one or both of these criteria. In conclusion, we have not seen a type of channel opening in either cell-attached or outside-out patches that can account for the depolarizing action of ATP.

\section{ATP sensitivity of chick muscle in vivo}

In two experiments, we tested the effect of ATP on muscles in $18 \mathrm{~d}$ old chick embryos. Individual muscles were dissected free from the hindlimb and pinned to the bottom of a Sylgard-coated dish. ATP $(50 \mu \mathrm{M})$ was applied from a puffer, and we observed the muscles through a dissecting microscope for any sign of contraction. We detected ATP-evoked contractions in some regions of the ambiens muscle of both embryos. However, many fibers did not contract. Whether this represents true variability in responsiveness or in access of ATP to its receptors was not assessed. In one of these experiments, the muscle was bathed in $\alpha$-bungarotoxin to ensure that all ACh receptors were blocked, and the block was verified by applying $\mathrm{ACh}$ from another puffer. These results indicate that ATP-evoked depolarizations are not restricted to cultured muscle.

\section{Synaptic transmission in $\alpha$-bungarotoxin blocked co-cultures}

The sensitivity of muscle membrane to ATP suggests the possibility that ATP plays a role as a neurotransmitter at the neuromuscular junction. To test this possibility, we took advantage of the observation that chick ciliary ganglion neurons form cholinergic synapses with cultured myotubes rapidly and with high probability (Betz, 1976; Crean et al., 1982; Nishi and Berg, 1977; Role et al., 1982). In control co-cultures, in which we stimulated individual ciliary ganglion neurons while recording intracellularly from adjacent myotubes, we found that $60 \%$ of the nervemuscle pairs $(21 / 35)$ were synaptically connected at $1-3 \mathrm{~d}$ of co-culture. We then added $\alpha$-bungarotoxin to sibling cultures and noted whether stimulation of the ciliary ganglion neurons led to any detectable depolarization. Since the ATP response of uninnervated myotubes is unaffected by concentrations of $\alpha$ bungarotoxin that completely block ACh receptors, any residual synaptic depolarization recorded in the presence of $\alpha$-bungarotoxin would have been interpreted as a putative ATP response. Myotubes in co-cultures were still sensitive to ATP (20 out of 28 fibers depolarized in response to $10 \mu \mathrm{M}$ ATP). However, neither single spikes nor repetitive trains $(5-10 \mathrm{~Hz}, 2-4 \mathrm{sec})$ of spikes evoked in the ciliary ganglion neurons gave a detectable depolarization in any of the myotubes ( 25 nerve-muscle pairs tested).

Thus, at present there is no evidence that ATP plays a functional role at these synapses.

\section{Discussion}

\section{Single-channel results}

In this study we have shown that ATP has a potent depolarizing action on chick myoblasts and myotubes in vitro and on embryonic muscle fibers in vivo. ATP acts by causing an increase in conductance. The process has a reversal potential near $0 \mathrm{mV}$, which is consistent with a channel that is relatively nonselective among cations. However, to our surprise, we saw no indication of single ATP-activated channels in a large sample of both outside-out and cell-attached patches. We find this puzzling since the vast majority of myoblasts and myotubes are depolarized by ATP. Furthermore, Kolb and Wakelam (1983) had reported that ATP opens cation channels of about 20 and $45 \mathrm{pS}$ in cultured chick myoblasts and myotubes. We do not understand the source of this discrepancy.

Failure to identify single channels might result if (1) the channels are incapable of opening under the experimental conditions, (2) the channel density is so low that the probability of en- 
countering a channel is beyond the patience of the experimenters, or (3) the single-channel conductance is so small that singlechannel currents are lost in the background noise.

An example of the first possibility is the observation that calcium channels from some cells lose the ability to open after patches are isolated (Fenwick et al., 1982). A likely explanation is that some factor in the cell interior, necessary for maintaining the channel in a functional state, is absent from the internal solution. Although this might explain the absence of singlechannel currents evoked by ATP in outside-out patches, it would not explain why we did not see ATP-activated channels in cellattached patches.

Desensitized channels might also be incapable of opening. The response we studied with intracellular recording decreases after a few seconds' exposure to ATP and shows no recovery for at least $20 \mathrm{~min}$ after the ATP is removed. One would therefore predict that the frequency of opening of the channels causing this response would rapidly decrease with time, perhaps over only a few seconds. We paid close attention to the first few seconds that ATP was applied to patches, but even then we were unsuccessful in detecting ATP-evoked single-channel currents. It should be noted that this predicted behavior of the ATP channels is very different from the behavior of the channels studied by Kolb and Wakelam. Rather than decrease with time, the frequency of the channel openings they studied increased with time after patch formation.

The second possibility is that the density of channels was below the limits of detectability. We tested nearly 200 patches without any evidence for single-channel currents evoked by ATP. Using $3 \mu \mathrm{m}^{2}$ as a minimum estimate of patch area, we have sampled almost $600 \mu \mathrm{m}^{2}$ of muscle surface without encountering a functional ATP-activated channel. Such a low density might still be consistent with the high probability of seeing whole-cell depolarizations. Dye-ejection experiments indicate that a drug applied from our puffer system superfuses many thousand square microns of muscle surface. Since the input resistance of these myotubes is high (often in excess of $100 \mathrm{M} \Omega$ ), only a few channels need to open to depolarize the cell significantly. If receptors are clustered, it is even less likely that they will be encountered by patch recording.

If any of the above possibilities are correct, it would imply that there was some important difference between the methods used by Kolb and Wakelam and ours. It seems to us that there are no significant differences in the recording methods, and only slight differences in our culture methods. In contrast to Kolb and Wakelam, we usually do not fusion-arrest the myoblasts; however, even when we studied fusion-arrested myoblasts, our results were no different. We cannot rule out the possibilities that therc may be significant differences related to the strain of chicken, or that an undefined component of the medium (in the embryo extract or serum) differs. That a component of the medium may drastically alter the number and distribution of cell surface receptors has precedents. For instance, extracts of brain can cause changes in the number and distribution of $\mathrm{ACh}$ receptors on cultured chick myotubes (Buc-Caron et al., 1983; Jessell et al., 1979).

The final possibility, that the single-channel conductance is very low, would imply that the 20 and $45 \mathrm{pS}$ channels described by Kolb and Wakelam are not related to the ATP response that we studied. Given our typical recording conditions (holding potential, -80 to $-100 \mathrm{mV}$; peak-to-peak noise, $0.3-1 \mathrm{pA}$ at $1000 \mathrm{~Hz}$ ), we would easily have detected a channel with a unit conductance even smaller than $20 \mathrm{pS}$. One piece of evidence suggests that the single-channel conductance may be small. As is shown in Figure 10, although $\mathrm{ACh}$ and ATP each caused a flow of inward current, ACh application resulted in an obvious increase in the noise above the background level, whereas there was no increase in noise during ATP application. Such noise is thought to represent fluctuations due to the random opening and closing of single channels (reviewed by Stevens, 1977). Under appropriate conditions, the amplitude of the fluctuations is directly proportional to the amplitude of the single-channel event; however, in our experiments, conditions were far from ideal for noise analysis. Whole-cell recording from myotubes does not provide an adequate space clamp, so the noise from channels that are far from the recording site will be attenuated by the membrane capacitance. Thus, a low noise level could result from relatively large, but distant, channels. However, the simplest interpretation of the low noise level in the ATP recordings is that the single channel activated by ATP has a very small conductance. Very low conductance events activated by nucleotides have a precedent (Fesenko et al., 1985).

Although our results can be explained by a channel with a small conductance, this interpretation does not explain what the channels that Kolb and Wakelam observed might then represent. The sizes of the single-channel events they recorded are similar to what one might expect to flow through a calciumactivated nonselective cation channel (Colquhoun et al., 1981; Yellen, 1982). Activity related to such channels has recently been recorded from cultured rat myotubes (Siegelbaum et al., 1984). Such channels might be activated indirectly, perhaps due to cell damage when forming seals (see also Siegelbaum et al., 1984), by calcium flux through the ATP channel, or by a rise in intracellular calcium, indirectly related to ATP action (Yatani et al., 1982). However, it is clear that flux through calcium channels is not necessary for ATP depolarizations, since ATP depolarizes myotubes placed in a calcium-free cobalt-containing external recording solution. This, of course, does not rule out an effect due to calcium flux through a cobalt-insensitive channel or to release of calcium from an internal store.

\section{Transmitter release from growth cones}

Whatever the reason for our failure to detect ATP-activated channels, this result has important ramifications for interpreting earlier work. Hume et al. (1983) showed that single-channel openings of $\sim 35 \mathrm{pS}$ could be recorded when outside-out patches of chick myotube membrane were placed ncar the growth concs of cholinergic neurons cultured in the absence of target cells. These channel openings were interpreted as being due to the evoked release of $\mathrm{ACh}$, since they were seen when the neurons were stimulated, and not seen when the recording medium contained curare. In light of Kolb and Wakelam's report, an alternative explanation of these results is that the active substance released from growth cones might be ATP. However, since the patches in our previous study were prepared in an identical manner to those reported here, it is likely that those patches also lacked detectable ATP-activated channels. Furthermore, since the whole-cell response to ATP is not blocked by curare, the curare sensitivity of the evoked growth cone release also implies that the active agent is $\mathrm{ACh}$. It should be noted that these arguments in no way rule out the possibility that ATP is released from growth cones upon stimulation; they simply indicate that we would not have noticed this by using outside-out patches of myotube membrane as detectors.

\section{ATP receptor function}

Single-channel recordings had raised the possibility that ATP might act as an agonist for the nicotinic ACh receptor (Kolb and Wakelam, 1983). Our results make this explanation seem extremely unlikely. Neither $\alpha$-bungarotoxin nor $d$-tubocurarine at concentrations that completely blocked $\mathrm{ACh}$ receptor function had a detectable effect on ATP responsiveness. Furthermore, desensitizing concentrations of ACh had no effect on ATP responsiveness. Thus, the only way that ATP could have its primary effect on ACh receptors would be if ATP caused both toxin-blocked receptors and desensitized receptors to open. This 
possibility seems unlikely to us. Furthermore, the presence of ATP did not noticeably alter the ACh response. Thus, the ATP effect we see differs from that observed in rat diaphragm (Ewald, 1976) and frog sartorius muscle (Akasu et al., 1981), where high concentrations of ATP enhance ACh sensitivity.

Another type of ATP response has been described by Gomperts and colleagues (Cockcroft and Gomperts, 1979; Gomperts, 1983). ATP applied extracellularly causes mast cells to become permeable to a variety of small molecules. However, ATP is effective at micromolar levels only if it is presented in the virtual absence of divalent cations. In all our experiments, the calcium and magnesium concentrations were each several millimolar, so it seems unlikely that we were dealing with a similar phenomenon.

Various nucleotide receptors have been described (see Burnstock, 1981, for review). One class of receptors $\left(P_{1}\right)$ is most sensitive to adenosine but can be activated by ATP, both directly and following hydrolysis of ATP to AMP and adenosine (Collis and Pettinger, 1982; Moody et al., 1984). Another class $\left(P_{2}\right)$ is most sensitive to ATP, with little if any sensitivity to adenosine. Since adenosine and AMP had no effect on myotube membrane potential, it is unlikely that we are dealing with $P_{1}$ receptor. However, the pharmacological profile of the ATP response of myotubes is different from that found for $P_{2}$ receptors in other systems. For instance, ADP had no detectable effect on myotubes (see also Kolb and Wakelam, 1983), while in several other systems it is a weak agonist. However, the most significant difference from other ATP receptors was in the response to nonhydrolyzable ATP-like substances (see, also, Silinsky and Ginsborg, 1983). Neither AMP-PNP, $\alpha, \beta$-meATP, nor $\beta, \gamma$-meATP showed agonist activity. In contrast, in vas deferens (Sneddon and Burnstock, 1984; Sneddon and Westfall, 1984), snail neurons (Yatani et al., 1982), and cultured dorsal horn neurons (Jahr and Jessell, 1983), one or more of these substances is at least as potent as ATP. Since AMP-PNP, $\alpha, \beta$-meATP, and $\beta, \gamma$-meATP are structurally very similar to ATP (an internal -O- linking two of the phosphate groups is replaced by an -NHor a $\left.-\mathrm{CH}_{2}-\right)$, it seems unlikely that such compounds would be excluded from an ATP reccptor on steric grounds. Perhaps a more likely possibility is that nonhydrolyzable analogs are without effect because the terminal phosphate group must be cleaved for ATP to act. The apparent difficulty with this scheme is that ATP- $\gamma-\mathrm{S}$ is a potent agonist. However, although ATP- $\gamma-\mathrm{S}$ is resistant to hydrolysis by ATPases and phosphatases, it can serve, unlike the other analogs, as a phosphate donor in reactions catalyzed by protein kinases (Gratecos and Fisher, 1974; Morgan et al., 1976). Thus, it seems possible that ATP acts by serving as a phosphate donor in an extracellular phosphorylation reaction.

\section{Physiological role of $A T P$ receptors}

In this study we have shown that ATP, at a concentration as low as $500 \mathrm{~nm}$, can evoke contraction when it is applied over a large area of the muscle surface. Although muscles themselves may release ATP (Israël et al., 1976), we were particularly interested in discovering whether ATP played a role as a synaptic transmitter at newly formed neuromuscular junctions. If we assume that the stoichiometry of ATP in vesicles is 1 ATP : 6 ACh (reviewed in Castel et al., 1984; Zimmermann, 1982), and that the local concentration of $\mathrm{ACh}$ in the synaptic cleft immediately after release is nearly $300 \mu \mathrm{M}$ (Kuffler and Yoshikami, 1975), then the ATP concentration in the cleft might reach 50 $\mu \mathrm{M}$ (see, also, Silinksy, 1975).

The ability to completely block ACh-evoked depolarization with $\alpha$-bungarotoxin allowed us to make preliminary tests of a postsynaptic role for ATP. In none of the nerve-muscle pairs tested in the presence of $\alpha$-bungarotoxin did we see any synaptic depolarization. Thus, at present, there is no evidence that ATP receptors play a role in synaptic transmission. However, the present experiments certainly do not rule out such a role. We did not measure ATP levels, so we do not know whether chick ciliary ganglion neurons contain and release ATP, or whether they differ in this regard from the spinal motoneurons that innervate skeletal muscle.

Furthermore, the rapid long-term desensitization of the ATP response complicates the interpretation of these results. Since at least some ciliary ganglion neurons in culture spike spontaneously at low frequency (Hume, unpublished observations), it is possible that the ATP receptors at synapses were desensitized before we were able to study them. This might mean that ATP receptors have only a transient functional role. Alternatively, there may be mechanisms that allow receptors to recover from desensitization in intact muscle that are not functional under our culture conditions. If so, it might be easier to demonstrate a synaptic effect of ATP at a developing neuromuscular junction in vivo.

\section{References}

Akasu, T., K. Hirai, and K. Koketsu (1981) Increase of acetycholinereceptor sensitivity by adenosine triphosphate: A novel action of ATP on ACh-sensitivity. Br. J. Pharmacol. 74: 505-507.

Betz, W. (1976) Functional and non-functional contacts between ciliary neurones and muscle grown in vitro. J. Physiol. (Lond.) 254: 7586.

Brehm, P., R. Kullberg, and F. Moody-Corbett (1984) Properties of non-junctional acetylcholine receptor channels on innervated muscle of Xenopus laevis. J. Physiol. (Lond.) 350: 631-648.

Buc-Caron, M. H., P. Nystrom, and G. D. Fischbach (1983) Induction of acetylcholine receptor synthesis and aggregation: Partial purification of low-molecular-weight activity. Dev. Biol. 95: 378-386.

Burnstock, G. (1981) Neurotransmitters and trophic factors in the autonomic nervous system. J. Physiol. (Lond.) 313: 1-35.

Castel, M., H. Gainer, and H. D. Pellman (1984) Neuronal secretory systems. Int. Rev. Cytol. 88: 303-459.

Cockcroft, S., and B. D. Gomperts (1979) Activation and inhibition of calcium-dependent histamine secretion by ATP ions applied to rat mast cells. J. Physiol. (Lond.) 296: 229-243.

Collis, M. G., and S. J. Pettinger (1982) Can ATP stimulate $P_{1}$-receptors in guinea pig atrium without conversion to adenosine? Eur. J. Pharmacol. 81: 521-529.

Colquhoun, D., E. Neher, H. Reuter, and C. F. Stevens (1981) Inward current channels activated by intracellular $\mathrm{Ca}$ in cultured cardiac cells. Nature 294: 752-754.

Crean, G., G. Pilar, J. B. Tuttle, and K. Vaca (1982) Enhanced chemosensitivity of chick parasympathetic neurones in co-culture with myotubes. J. Physiol. (Lond.) 331: 87-104.

Dale, H. H., W. Feldberg, and M. Vogt (1936) Release of acetylcholine at voluntary motor nerve endings. J. Physiol. (Lond.) 86: 353-380.

Ewald, D. A. (1976) Potentiation of postjunctional cholinergic sensitivity of rat diaphragm muscle by high-energy-phosphate adenine nucleotides. J. Membr. Biol. 29: 47-65.

Feltz, A., and A. Trautmann (1982) Desensitization at the frog neuromuscular junction: A biphasic process. J. Physiol. (Lond.) 322: 257272.

Fenwick, E. M., A. Marty, and E. Neher (1982) Sodium and calcium channels in bovine chromaffin cells. J. Physiol. (Lond.) 331: 599_ 635.

Fesenko, E. E., S. S. Kolesnikov, and A. L. Lyubarsky (1985) Induction by cyclic GMP of cationic conductance in plasma membrane of retinal rod outer segment. Nature 313: 310-313.

Fischbach, G. D. (1972) Synapse formation between dissociated nerve and muscle cells in low density cell cultures. Dev. Biol. 28: 407-429.

Fukuda, J. (1974) Chloride spike: A third type of action potential in tissue-cultured skeletal muscle cells from the chick. Science 185: 7678.

Fukuda, J., G. D. Fischbach, and T. G. Smith, Jr. (1976) A voltage clamp study of the sodium, calcium and chloride spikes of chick skeletal muscle cells grown in tissue culture. Dev. Biol. 49: 412-424.

Furshpan, E. J., P. R. MacLeish, P. H. O'Lague, and D. D. Potter (1976) Chemical transmission between rat sympathetic neurons and cardiac myocytes developing in microcultures. Evidence for cholinergic, ad- 
renergic and dual function neurons. Proc. Natl. Acad. Sci. USA 73: $4225-4229$.

Gomperts, B. D. (1983) Involvement of guanine nucleotide-binding protein in the gating of $\mathrm{Ca}^{2+}$ by receptors. Nature 306: 63-66.

Gratecos, D., and E. II. Fischer (1974) Adenosine 5'-O(3-thiotriphosphate) in the control of phosphorylase activity. Biochem. Biophys. Res. Commun. 58: 960-967.

Guharay, F., and F. Sachs (1984) Stretch-activated single ion channel currents in tissue-cultured embryonic chick skeletal muscle. J. Physiol. (Lond.) 352: 685-701.

Hamill, O. P., A. Marty, E. Neher, B. Sakmann, and F. J. Sigworth (1981) Improved patch-clamp techniques for high-resolution current recording from cells and cell-free membrane patches. Pfluegers Arch. 351: $85-100$.

Hökfelt, T., O. Johansson, and M. Goldstein (1984) Chemical anatomy of the brain. Science 225: 1326-1334.

Hume, R. I., and M. G. Honig (1984) Acetylcholine-like action of ATP on cultured chick myotubes. Neurosci. Abstr. 10: 581.

Hume, R. I., L. W. Role, and G. D. Fischbach (1983) Acctylcholine release from growth cones detected with patches of acetylcholine receptor-rich membranes. Nature 305: 632-634.

Ii, I., I. Kimura, and E. Ozawa (1982) A myotrophic protein from chick embryo extract: Its purification, identity to transferrin, and indispensability for avian myogenesis. Dev. Biol. 94: 366-377.

Israël, M., B. Lesbats, F. M. Meunier, and J. Stinnakre (1976) Postsynaptic release of adenosine triphosphate induced by single impulse transmitter action. Proc. R. Soc. Lond. [Biol.] 193: 461-468.

Jackson, M. B. (1984) Spontaneous openings of the acetylcholine receptor channel. Proc. Natl. Acad. Sci. USA 81: 3901-3904.

Jahr, C. E., and T. M. Jessell (1983) ATP excites a subpopulation of rat dorsal horn neurones. Nature 304: 730-733.

Jan, Y. N., C. W. Bowers, D. Branton, L. Evans, and L. Y. Jan (1983) Peptides in neuronal function: Studics using frog autonomic ganglia. Cold Spring Harbor Symp. Quant. Biol. 48: 363-374.

Jessell, T. M., R. E. Siegel, and G. D. Fischbach (1979) Induction of acetylcholine receptors on cultured skeletal muscle by a factor extracted from brain and spinal cord. Proc. Natl. Acad. Sci. USA 76: 5397-5401.

Johnson, M. I., D. Ross, M. Meyers, R. Rees, R. Bunge, E. Wakshull, and $H$. Burton (1976) Synaptic vesicle cytochemistry changes when cultured sympathetic neurones develop cholinergic interactions. $\mathrm{Na}$ ture 262: 308-310.

Kano, M. and Y. Shimada (1973) Tetrodotoxin-resistant electric activity in chick skeletal muscle cells differentiated in vitro. J. Cell Physiol. 81: 85-90.

Kano, M., Y. Shimada, and K. Ishikawa (1972) Electrogenesis of cmbryonic chick skcletal muscle cells differentiated in vitro. J. Cell Physiol. 79: 363-366.

Kolb, H.-A., and M. J. O. Wakelam (1983) Transmitter-like action of ATP on patched membranes of cultured myoblasts and myotubes. Nature 303: 621-623.

Krishtal, O. A., S. M. Marchenko, and V. I. Pidoplichko (1983) Receptor for ATP in the membrane of mammalian sensory neurones. Neurosci. Lett. 35: 41-45.

Kuffler, S. W., and D. Yoshikami (1975) The number of transmitter molecules in a quantum: An estimate from iontophoretic application of acetylcholine at the neuromuscular junction. J. Physiol. (Lond.) 251: 462-482.

Landis, S. C., and D. Keefe (1983) Evidence for neurotransmitter plasticity in vivo: Developmental changes in propertics of cholinergic sympathetic neurons. Dev. Biol. 98: 349-372.

Moody, C. J., and G. Burnstock (1982) Evidence for the presence of $\mathrm{P}_{1}$-purinoceptors on cholinergic nerve terminals in the guinea-pig ileum. Eur. J. Pharmacol. 77: 1-9.

Moody, C. J., P. Meghji, and G. Burnstock (1984) Stimulation of $\mathrm{P}_{1-}$ purinoceptors by ATP depends partly on its conversion to AMP and adenosine and partly on direct action. Eur. J. Pharmacol. 97: 47-54.

Morgan, M., S. V. Perry, and J. Ottaway (1976) Myosin light-chain phosphatase. Biochem. J. 157: 687-697.

Nishi, R., and D. K. Berg (1977) Dissociated ciliary ganglion neurons in vitro: Survival and synapse formation. Proc. Natl. Acad. Sci. USA 74: 5171-5175.

Paterson, B., and R. C. Strohman (1972) Myosin synthesis in cultures of differentiating chicken embryo skclctal musclc. Dev. Biol. 29: 113138.

Role, L. W., R. I. Hume, and G. D. Fischbach (1982) Transmitter release and receptor aggregation at ciliary neuron-muscle synapses. Neurosci. Abstr. 8: 129.

Shainberg, A., G. Yagil, and D. Yaffe (1971) Alterations of enzymatic activities during muscle differentiation in vitro. Dev. Biol. 25: 1-29.

Siegelbaum, S. A., A. Trautmann, and J. Koenig (1984) Single acetylcholine-activated channel currents in developing muscle cells. Dev. Biol. 104: 366-379.

Silinsky, E. M. (1975) On the association between transmitter secretion and the release of adenine nucleotides from mammalian motor nerve terminals. J. Physiol. (Lond.) 247: 145-162.

Silinsky, E. M., and B. L. Ginsborg (1983) Inhibition of acetylcholine release from preganglionic frog nerves by ATP but not adenosine. Nature 305: 327-328.

Sneddon, P., and G. Burnstock (1984) Inhibition of excitatory junction potentials in guinea-pig vas deferens by $\alpha, \beta$-methylene ATP: Further evidence for ATP and noradrenaline as co-transmitters. Eur. J. Pharmacol. 100: 85-90.

Sneddon, P., and D. P. Westfall (1984) Pharmacological evidence that adenosine triphosphate and noradrenaline are co-transmitters in the guinea-pig vas deferens. J. Physiol. (Lond.) 347: 561-580.

Stevens, C. F. (1977) Study of membrane permeability changes by fluctuation analysis. Nature 270: 391-396.

Takeuchi, A., and N. Takeuchi (1960) On the permeability of endplate membrane during the action of transmitter. J. Physiol. (Lond.) 154: 52-67.

Yatani, A., Y. Tsuda, N. Akaikc, and A. M. Brown (1982) Nanomolar concentrations of extracellular ATP activate membrane Ca channels in snail neurones. Nature 296: 169-171.

Yellen, G. (1982) Single $\mathrm{Ca}^{2+}$-activated nonselective cation channels in neuroblastoma. Nature 296: 357-360.

Zimmermann, H. (1982) Biochemistry of the isolated cholinergic vesicles. In Neurotransmitter Vesicles, R. L. Klein, H. Lagercrantz, and H. Zimmermann, eds., pp. 271-304, Academic, New York. 